Article

\title{
The Potential of Food Packaging Attributes to Influence Consumers' Decisions to Sort Waste
}

\author{
Babak Nemat ${ }^{1, *(\mathbb{D})}$, Mohammad Razzaghi ${ }^{2}$, Kim Bolton $^{1}$ and Kamran Rousta ${ }^{1}$ (D) \\ 1 The Swedish Centre for Resource Recovery, University of Borås, SE-501 90 Borås, Sweden; \\ kim.bolton@hb.se (K.B.); kamran.rousta@hb.se (K.R.) \\ 2 Department of Industrial Design, Faculty of Applied Arts, University of Art, Tehran 1136813518, Iran; \\ m.razzaghi@art.ac.ir \\ * Correspondence: babak.nemat@hb.se; Tel.: +46-768-700-054
}

Received: 23 January 2020; Accepted: 6 March 2020; Published: 13 March 2020

check for updates

\begin{abstract}
Food packaging waste is a valuable resource for material recovery, if it is properly separated and sorted by consumers. The packaging itself may have the potential to assist consumer sorting by, for example, communicating a correct sorting practice. This is partly due to the fact that the sorting of packaging waste, which is a habitual behavior of consumers, can be perceived as being confusing and inconvenient. Consumers can, therefore, choose not to sort. It is argued that material recovery could be enhanced if packaging can afford easy and proper sorting and separation. To investigate the potential of packaging to support proper sorting, six types of yogurt and cream packaging were examined across 15 households in Karlskrona (a medium-sized Swedish city). The aim is to investigate the effect of selected packaging attributes on consumer decisions regarding waste sorting. The results reveal that some of the selected packaging waste is not properly separated and sorted. It is concluded that the design of food packaging based on user-centered needs could affect consumer decisions for the proper sorting of packaging waste, which enables improved material recovery. The design should focus especially on the package's visual attributes, the material selection, and the package's waste sorting related functions.
\end{abstract}

Keywords: household waste; packaging waste; recycling behavior; waste separation; dairy packaging

\section{Introduction}

A growing world population, combined with changes in consumption patterns, is leading to a rapid increase in municipal solid waste (MSW). MSW is expected to increase from 2.01 billion tons in 2016 to 3.40 billion tons in 2050 [1]. This amount of waste could result in significant economic, social and environmental problems in most parts of the world. For this reason, sustainable waste management has become a priority for all countries [2]. The vast amounts of packaging waste, as well as the diversity of materials used to produce packaging, has made it one of the MSW fractions that are most challenging for sustainable waste management [3]. In the United States, packaging was 29.7\% of the total MSW in 2015 [4]. In Europe, approximately $170 \mathrm{~kg}$ of packaging waste was generated per person in 2017, while the total amount of generated waste per person was $487 \mathrm{~kg}$ [5]. In Sweden, packaging waste was $21 \%$ of the MSW in 2017 [6]. In total, the global packaging waste forms $30-35 \%$ of the MSW [7-9], and almost 60\% of all packaging is for food products [9-11]. In addition, a large amount of materials is used to produce food packaging. For example, $42 \%$ of the global production of plastic, which is approximately 141 million tons per year, is used for food packaging [12]. At the same time, the recycling rate is less than five percent $[12,13]$. As a result, several policies and strategies have been developed to deal with packaging waste. The European Union (EU) set a target to recycle $70 \%$ of all packaging waste by 2030 [8]. 
Sweden has also decided to increase the current recycling rate for packaging waste from $65 \%$ by $20 \%$ per year [14]. The primary rationale behind this is that waste is a potential resource for material recovery and energy production [15], if it is properly separated by consumers, which is highly dependent upon the voluntary engagement of consumers with the technical system [16]. Sorting of waste by consumers makes the entire recycling process more cost-effective than separation and sorting at a material recovery facility, where all of the waste is initially mixed, and the quality and quantity of the sorted fractions are low [17]. Therefore, separating and sorting the different waste fractions is essential for effective recycling, and accordingly, is viewed as a respected responsibility of households in sustainable waste management systems $[18,19]$.

Improving recycling rates requires more than just the technical development of waste management systems, and a great deal of emphasis has been placed on strategies to promote the role of citizens in the system. For instance, in Sweden, to facilitate the sorting practice, various types of facilities are considered by municipalities. These are bring/drop-off points (i.e., recycling stations) or property-close collection stations. A property-close collection station is usually located near the residential area, as opposed to the bring/drop-off points, and can be implemented in different ways, depending upon the residential conditions and the municipality's plans for waste collection. The most common types of property-close collection stations are the two-bin system, the comingled collection of dry recyclables, separate bins for different recyclable materials, multi-compartment bins, optical sorting, and food waste separation. In addition to these facilities, the producer responsibility law has probably led to the largest improvement in Sweden's waste management. According to this law, producers are responsible for the safe collection, transporting and disposal of specific types of waste, e.g., packaging, tires, and graph paper. Nowadays, most Swedish producers work in affiliation with the FTI (FTI, förpacknings och tidningsinsamlingen in Swedish (the packaging and newspaper collection)) to promote their sustainable businesses, and to meet their obligations as producers [20]. Producers are also responsible for reducing the environmental impacts of their products and to provide municipalities with information to deal with production waste. Municipalities, on the other hand, are responsible for providing residents with relevant information, and residents are expected to separate and sort different waste fractions in their homes, i.e., sorting at the source [16,21]. Therefore, such a system must avoid confusion and inconvenience for the residents. For instance, in some brochures provided by Swedish municipalities, about 200 different MSW items are listed, and information is given on how to sort them into ten different waste bins. If there is inadequate information, consumers will not be sure of how and to what extent these items must be separated and sorted. Furthermore, waste sorting in Sweden is a moral obligation, and there is no penalty for not sorting correctly [17]. Research conducted by Rousta et al. (2013) [22] showed that perceived inconvenience by residents can hinder proper sorting, and that paper and plastic packaging waste has higher rates of miss-sorting, due to a large distance between the local collection system and the residential area.

Since a large part of the packaging is used for food products, and food packaging is the most substantial part of missorted fractions in household waste, it is important to identify any factors that can encourage consumers to sort food packaging waste. The first contact that consumers have with packaged food is the packaging. This packaging has structural, graphical and verbal attributes. Packaging structural attributes include the type of material from which the packaging is made, and the shape and size of the packaging. Graphical attributes include the color of the packaging, as well as the labels and symbols that may be found on the packaging. Verbal attributes include information that is in the form of text [23]. A combination of these attributes enables food packaging to be a service provider to the consumer by offering different functions, such as being easy to open, or features such as a sense of the quality of the packaging and the packaged product [24]. The level of consumer satisfaction with the service, whether it be positive or negative, could influence consumer interaction with the packaging, i.e., communication between the consumer and the packaging [25]. Therefore, understanding which factors hinder consumers from proper sorting could enable packaging designers to utilize the potential 
of packaging to communicate with consumers, and thereby effect their behavior [26,27]. This could facilitate the sorting and recycling of the packaging waste [28].

There have been extensive investigations to identify the impact that food packaging attributes can have on consumer behavior, and how improving these attributes can support proper recycling and sorting [26,29-32]. Various factors have been identified that can hinder recycling behavior, such as uncertainty [33], difficulty to empty, clean, fold and separate the packaging, and perceived inconvenience when sorting [26,34-36]. A wide range of packaging functions and attributes that can reduce these effects have been proposed by researchers. These include easy to empty, easy to clean, easy to reseal, easy to compact/fold, easy to separate, recycling symbols and packaging features that can be perceived as providing additional value and convenience $[34,35,37,38]$. The current knowledge, however, is too general, and different types of packaging that have varying attributes may influence consumer behavior in different ways [39]. For example, large or heavy packaging has been identified as being problematic for sorting by consumers [26,29,40], but the terms 'large' or 'heavy' are not explicitly defined. Similarly, the materials used in the packages can be perceived by consumers as providing value, and this can positively affect their recycling behavior [34]. However, it is still not clear if other attributes of packaging can be perceived as providing 'value', and whether or not it would be the same for all types of packaging.

It can also be noted that there is less focus on waste sorting than on other parts of the waste management system, and this term is usually studied in parallel or included with recycling, so-called recycling behavior, e.g., [41-43]. There are only a limited number of studies that focus only on waste separation and sorting of packaging waste, e.g., [34,36].

Hence, it is of interest to understand the influence that specific types of packaging and packaging attributes can have on consumer separating and sorting behavior. This includes developing knowledge regarding the packaging functions and features, and how these are aligned with consumer needs during the separation and sorting of the waste [44]. This is of critical importance during the sorting of waste, since the consumers may perceive that the packaging loses its value directly after the contents have been used, and the fact that the packaging becomes a 'waste' product may influence its relationship with the consumer [34]. In addition, waste sorting is a routine task for consumers, and is often conducted without conscious thought. Consumers become aware of their actions when they encounter an obstacle that hinders their behavior [33]. However, the unconscious mind is a pool of thoughts, memories, and feelings that shape more than $95 \%$ of human activities [45,46]. Hence, it is plausible that proper product design that can meet functionality, usability and consumer satisfaction can affect the unconscious consumer behavior in an intended way $[47,48]$. This requires an in-depth knowledge of consumer perceptions to identify the key factors (packaging attributes) that affect consumer behavior [49]. An example is the recent Coca Cola ${ }^{\mathrm{TM}}$ campaign in Sweden (2020) to promote the sorting of plastic bottles [50].

The purpose of the current study, therefore, is to deepen our understanding of how particular attributes of specific types of food packaging can influence the decisions that consumers make during the separation and sorting of packaging waste at home. The study is intended to supply feasible suggestions for packaging developers, by interpreting consumers' statements and perceptions about packaging functions and attributes. This has not been the focus of previous investigations. The understanding that is gained from this type of study aims to improve the design of selected packaging so that it can support correct separation and sorting.

\section{Factors That Influence Consumer Separating and Sorting Behavior and Their Relationship to Packaging Attributes}

Previous investigations have identified different factors that influence consumer recycling behavior. These include (1) sociodemographic factors, such as age, gender and level of education, (2) internal factors, such as attitudes, beliefs, level of knowledge regarding which materials are recyclable, motivation and social norms, and (3) external factors, such as the distance between the living place 
and the recycling station, government intervention, collection services and costs [51-53]. A literature review by Nemat et al. [54] revealed that within studies that focused on 'food packaging attribute' and 'recycling/sorting behavior', five of these factors were most often mentioned as being affected by food packaging attributes.

These are: (1) attitude, (2) uncertainty and recycling knowledge, (3) packaging functions, (4) perceived quality/value, and (5) perceived convenience. These factors are focused on in the present study, and are discussed in more detail below. The literature review, which was limited to household waste sorting, showed which food packaging attributes could affect each of these factors.

\subsection{Attitude}

Two of the most recognized models that are used to explain recycling behavior, the theory of reasoned action [55] and the theory of planned behavior [56], agree that consumer attitude (the person's evaluation of favoring or not favoring the action) and environmental knowledge (awareness of environmental issues) are important predictors of consumer recycling behavior. Consumers with a positive attitude are more motivated to recycle [55-59]. The attitude itself can be affected by environmental knowledge [57]. A higher level of environmental knowledge increases the probability that consumers sort their waste $[57,58]$. Several studies showed that attitude can be influenced by the material that the packaging is made from, especially when consumers believe that recycling the material can have a significant environmental impact [59]. Materials such as paper and metal, which are perceived as being recyclable, encourage consumers to separate and sort the packaging for recycling, whereas materials such as plastic can negatively affect the consumer attitude [34,59]. Large food packaging can also negatively influence this consumer attitude, since the bigger size may imply a higher amount of food waste and difficulty with emptying and cleaning, which would subsequently be time-consuming activities (Consumers are usually only instructed to separate and sort packaging waste. However, as discussed below, many consumers empty and even clean the packages before separation and sorting). Contrary to this, some visual attributes of food packaging, such as anti-littering and ecofriendly labels, as well as recycling symbols, can appeal to consumer environmental awareness, and hence have a positive effect on consumer attitude [35].

\subsection{Uncertainty and Recycling Knowledge}

Several studies have found a positive correlation between recycling knowledge and recycling behavior $[60,61]$. In order to recycle packaging waste correctly, consumers often need knowledge of, for example, which products are packaging or non-packaging, the materials that the packaging is made from, as well as their recyclability, how to separate the different materials in a given package, and where to sort them (location of recycling containers) [62]. Therefore, access to adequate information would enhance recycling behavior by reducing consumer uncertainty [62]. Packaging can be one of the best carriers of this information, whether the information is communicated consciously or unconsciously, since it can provide information that is relevant for the given package and at the time when this information is needed [63]. However, this is not a trivial task, since consumers are surrounded by large amounts of information, so that the information may be disregarded [57]. Also, since paying attention to information is a voluntary task, consumers who are not interested in recycling may ignore the information [61], especially if it is difficult to read or understand [35]. Therefore, for products that are purchased regularly, like food, explicit visual attributes, such as color, labels, logos and symbols, have a critical role in attracting consumer attention [64-66]. These visual attributes are unconscious [67], so that they are more easily perceived by the consumer [68], in contrast to verbal attributes, i.e., written information that requires more effort to be perceived by consumers.

\subsection{Packaging Functionsg}

A product is defined by its attributes. These attributes enable or restrict consumers to act in a certain way, and they change consumer experience [28]. Similarly, the functions that the packaging provides 
can, together with its attributes, be a promising way to influence consumer behavior, experiences and perceptions about recycling [36]. Food packaging has primary functions, such as containment, apportionment, protection and a communication channel to the consumer.

Packaging can also provide functions such as being easy to empty, easy to clean, easy to separate, easy to compress (after usage), easy to re-seal, as well as information on how to sort. These various functions can be obtained by combining different packaging attributes. For example, the shape of the packaging and the material from which it is made affect the functions that are offered by the packaging [69].

\subsection{Perceived Quality/Value}

There is a strong correlation between the perceived quality/value of the food packaging waste and consumer intention to separate and sort. A study by Langley et al. [34] showed that consumers have a stronger intention to recycle if they perceive that the packaging has high quality, i.e., if they perceive that the packaging has high economic value. For example, glass is recycled more than other fractions, and plastic films are often sorted in mixed waste. Another study showed that consumers are reluctant to recycle a package if it is crumpled or torn, even if they know that it can be recycled [70]. The visual attributes of packaging, such as shape, color and material, can also affect the perceived quality of the packaging [71]. The perceived quality/value can also be affected by information on the packaging, individual consumer preferences, form and function [72,73].

\subsection{Perceived Convenience}

Although factors such as attitude and recycling knowledge may influence consumer motivation to sort, consumers often perceive that they are better at sorting than they are [74,75]. This could be due to several factors, including perceived convenience. The perceived convenience to recycle varies among different consumers. However, in general, consumers are more likely to separate and sort packaging waste if it is not perceived as being too inconvenient. Aspects that affect consumers' perception of convenience include a lack of proper information at the time of sorting, and the time, space, and effort needed to perform the separation and sorting [36-40]. Attributes of food packaging can also influence the perceived convenience. For example, providing symbols that indicate packaging recyclability is perceived as increasing the convenience by consumers [35], since this type of information can enhance consumer recycling knowledge. Other packaging functions, such as the difficulty to empty or to clean, are commonly perceived as an inconvenience, since both require additional effort, and are time consuming [34-37]. Also, large and heavy food packaging can be perceived as being inconvenient for recycling and sorting, since it can be difficult to transport, or to empty and clean $[26,29,40]$. As a conclusion from Section 2, the key aspects that are discussed above are summarized in Table 1.

Table 1. Five main factors that can influence sorting behavior and the packaging attributes that can affect them.

\begin{tabular}{cccccc}
\hline & \multicolumn{4}{c}{ The Food Packaging Attribute } \\
\hline Factors & Label/Symbol/Logo & Form/Shape & Material & Color & Size \\
\hline Attitude & $X$ & $X$ & & $X$ \\
Uncertainty and Recycling knowledge & $X$ & & $X$ & & \\
Packaging function & $X$ & $X$ & $X$ & & $X$ \\
Perceived quality & & $X$ & $X$ & $X$ & $X$ \\
Perceived convenience & $X$ & $X$ & $X$ & & \\
\hline
\end{tabular}

\section{Methods and Materials}

The research approach, including materials for selecting data and the type of interview, was based on user-centered design (UCD). This method places consumer needs at the core of the study in order to understand their experiences, choices and options when using products or services, and to identify 
factors that influence consumer perception [76]. It consists of three main phases: (1) inspiration, including identifying the problems encountered by the consumers and their demands, and that was used in the present study to plan interviews (2) ideation, including finding a proper solution, and that was used to generate appropriate suggestions for discovered problems, and (3) implementation [77]. The aim was to understand consumer behavioral problems and demands during the separating and sorting of food packaging waste, and how food packaging attributes can influence them. Desired results can be achieved by obtaining participant feedback, including open-ended discussions, and maintaining an interaction where participants feel free to act and make decisions that are normal in their every-day life [78]. Interviews were conducted through free discussions to collect data, since this method provides a useful way to penetrate participants' thoughts [79]. Moreover, interviews are perceived as being more informal than other methods such as surveys, and this enables participants to feel more comfortable and to freely share their thoughts, feelings and experiences [80]. In this way, the researcher has more chance of empathizing with the participants. However, a free discussion can be difficult to end. Hence, to narrow the free discussion, predetermined questions were designed and used to guide the interviews.

The research was conducted in Karlskrona, a medium-sized city in the south of Sweden. The invitations to the potential participants to take part in the experiment were managed by one the authors via networks of friends. 24 families were approached by speaking directly, phoning or e-mailing them. The research intention, estimated duration, expectations, and the need for direct interviews, were explained to the participants before they decided to participate in the study. Fifteen families, which included 37 people, agreed to participate. The group contained participants with different types of jobs, income, age, levels of education and types of housing.

Yogurt and cream packaging were selected to study explicit examples of how the participants decide to separate and sort their packaging waste. Yogurt and cream, respectively, have a second and third place in dairy consumption after ordinary milk in Sweden [81]. They also have a higher viscosity than milk, and hence they are more likely to adhere to the packaging surface. This can be perceived as an obstacle to separate and sort if the consumers want to empty and clean the packaging waste before sorting. Williams et al. [37] recommend that specific and commonly used types of packaging should be used in studies, so that the participants can easily remember their experiences. Therefore, six different types of packages that are commonly sold by companies in Sweden (e.g., ICA, Willys, Coop, Netto and Lidl) were selected. These are illustrated in Table 2, where the gray images in the right column were used when communicating with the participants.

The packaging is primarily produced from paperboard (The paperboard packaging studied here also contains plastic films as part of the carton. However, consumers are expected to sort these cartons as paperboard waste and the plastic cap, when it exists, as plastic waste. Paperboard is the most popular material for food packaging from the consumers' point of view [82], and has accounted for $35.7 \%$ of the global packaging consumption in 2016 [83]. As shown in Table 2, Type A is the only package that contains no plastic cap, Types $C$ and $E$ have a cap at the top of the carton, which enables easy emptying, cleaning and separating (according to the information on the package). Types B, D and $E$ have caps on the side of the carton, and Types $B$ and $E$ are the standard packaging types for yogurt and cream, respectively. Types A, B and C contain $1000 \mathrm{cc}$ of yogurt, and Types E and F contain $500 \mathrm{cc}$ and $300 \mathrm{cc}$ of cream, respectively. They are all common sizes in Sweden for yogurt [37] and cream. Types $\mathrm{D}$ and $\mathrm{F}$ are the biggest and smallest types, respectively. This diversity in packaging enabled the participants to share experiences of separating and sorting packages that have different attributes.

Among the 15 families included in the study, five families lived in houses and used a two-bin system (one intended for food waste and the other for combustible waste) for collecting and sorting their waste. Packaging waste must be separated beforehand and then transferred to the recycling station (bring system). Waste from the two-bin system is usually collected twice a week, and one company is responsible for collection [84]. The remaining families live in apartments and use a property-close system that consists of different trash bins that are located in one room ('Miljörum' in Swedish) near 
the residential area. These bins are used to collect different types of waste, including paper, plastic and glass packaging. The process for collecting waste, however, is different, and depends on which company holds a contract with the residential landlord.

Table 2. Different types of packaging used in the research. The gray forms are the symbols for each type of packaging.

Available Packages
Type A-1000 cc
Yogurt without cap


The packaging waste considered in this study consists of two types of material (paperboard and plastic) that should be sorted into bins for paper and plastic waste, as recommended by producers and legislations established by FTI. Since the participants in this study have easy access to recycling systems, the focus is on participants' sorting activities in their living places.

The participants were asked to include these types of packaging when performing their daily shopping during the month before the interview, regardless of the brand of dairies. This gave them time to experience the packaging, including separating and sorting the waste before the interview. This increased the probability of obtaining data from their real experiences, rather than their assumed experiences. The interviews were recorded and transcribed for further analysis and interpretation.

\section{Data Collection}

Open-ended interviews were used to understand the influence of the factors that were discussed in Section 2, Table 1 on participants' behavior during waste sorting. The interviews were guided by questions, as listed in Table 3. Each question was designed to address specific factors. The factors that are addressed by each of the questions are summarized in Table 3 and discussed in detail below.

Table 3. The interview questions (Q1-Q10) and the factors that can influence separation and sorting, and that are addressed by these questions.

\begin{tabular}{|c|c|c|c|c|c|}
\hline Questions & $\begin{array}{l}\text { Attitude to } \\
\text { Recycling }\end{array}$ & $\begin{array}{l}\text { Packaging } \\
\text { Functions }\end{array}$ & $\begin{array}{l}\text { Uncertainty } \\
\text { \& Recycling } \\
\text { Knowledge }\end{array}$ & $\begin{array}{c}\text { Perceived } \\
\text { Quality/Value }\end{array}$ & $\begin{array}{c}\text { Perceived } \\
\text { Convenience }\end{array}$ \\
\hline $\begin{array}{l}\text { Q1. How do you rate yourself in } \\
\text { recycling/sorting? }\end{array}$ & $\mathrm{X}$ & & & & \\
\hline $\begin{array}{l}\text { Q2. How did you gain your recycling } \\
\text { knowledge? How did you learn to do recycling? }\end{array}$ & $\mathrm{X}$ & $\mathrm{X}$ & $X$ & & \\
\hline $\begin{array}{l}\text { Q3. How do you recycle dairy (yogurt and } \\
\text { cream) packaging waste at home? }\end{array}$ & & & $\mathrm{X}$ & & $x$ \\
\hline $\begin{array}{l}\text { Q5. Did you notice to the labels/symbols on } \\
\text { packaging? Do you know the meaning of them? }\end{array}$ & $X$ & $X$ & $x$ & & $x$ \\
\hline Q6. Did you notice the images on packages? & & $X$ & $X$ & & $X$ \\
\hline $\begin{array}{l}\text { Q7. Which color combination of these packages } \\
\text { may decrease the risk that they are sorted with } \\
\text { mixed waste? Why? }\end{array}$ & & & & $X$ & \\
\hline $\begin{array}{l}\text { Q9. Which size of these packages is suitable for } \\
\text { recycling? Why? }\end{array}$ & $X$ & & & $x$ & $X$ \\
\hline $\begin{array}{l}\text { Q10. Which type of these packages did you find } \\
\text { more suitable/easy for recycling? Why? }\end{array}$ & & $x$ & $x$ & $x$ & $x$ \\
\hline
\end{tabular}

The interviews were conducted separately for each of the participants, and mostly performed in their living places. It was clarified that the research focus is not on their actions/behavior, and is not a basis for judgment, but rather performed to understand the factors which cause (i.e., packaging attribute) their actions/behavior. The participants had a wide range of age, professions and education, and thus had different levels of recycling knowledge. Hence, their perception of some terms such as 'value,' 'quality', or 'recyclability', was not the same, which required additional explanations during the interviews. It was, therefore, necessary to ask the questions and manage the interviews in different ways. The language was another factor that amplified the above situation, thus making the interviews different from each other. The interviews were usually performed using a mixture of Swedish and English. The interviews were therefore done with the assistance of a Swedish person who was also good in English. Some interviewees also gave permission to record the interviews as an audio file, and all interviews were carefully transcribed and translated. The participants' statements were compared, and common themes were identified. Irrespective of the duration or language of these interviews, they were all started by the participants evaluating their recycling knowledge (Q1) to understand how the participants perceive their behavior. People in developed countries such as Sweden usually have 
a higher recycling knowledge [85], so Q2 was designed to identify the most common sources used to gain this knowledge.

Previous studies have shown that the separation and sorting of food packaging waste are usually preceded by emptying the package after use $[86,87]$. Only separation and sorting, and not emptying, are usually recommended by those sources and instructions related to waste management $[86,87]$. Hence, the next part of the interview $(\mathrm{Q} 3)$ was dedicated to understanding whether the participants performed the same steps as given by instructions, or if the participants had different steps prior to, or during, separation and sorting. The participants were also asked to explain the process of separating food packaging waste. Questions Q4-Q7 focused on the verbal (i.e., written text) and visual attributes of food packaging such as symbols, signs and colors. Question Q8 aims to identify the packaging and packaging attributes that gave the largest impression of quality/value. Question Q9 was intended to identify the effect of the different packaging sizes on their sorting. The last Question (Q10) compared the functions of the packaging that influence sorting behavior.

\section{Results and Discussions}

The self-evaluation Question (Q1) was analyzed to ascertain the participants' levels of motivation for practicing waste sorting, their general and specific knowledge in this matter, and how frequently they sort waste. Most participants believed that they were good at sorting waste. In response to Question $(\mathrm{Q} 2)$, the information about recycling that was provided by the participants' relatives, friends, neighbors, or landlord, was stated by participants as the main source. A few stated that they relied upon information that they received from school and the Internet, while TV and the radio were rarely given as a source. Only four of the 37 participants considered the packaging as the primary source to obtain recycling knowledge. The responses to (Q1) showed that the participants were aware of the benefits of sorting the packaging, but most of them did not use the packaging as a possible source of information to promote their separation and sorting. According to the participants' statements, this is due to that fact that gaining information from the packaging (as a source) was not considered by them, and a few participants said that they did not need to look for information on the packaging, since they trust the information obtained from other sources. In the next part of the interview (Q3), the participants described the detailed steps for the sorting of the packaging waste. This was done by repeating the actions during the interview, or by recalling from memory. Comparing the statements revealed three main intentions of the participants. One group regarded themselves as highly motivated for sorting waste, and they tried not to neglect the task, and were classified as 'always'. The ones who were aware of the benefits of sorting waste, while at the same time neglecting it on occasions, are classified as 'sometimes', and the ones who were neither motivated, nor cared about sorting, were classified as 'never'. The results are summarized in Table 4.

Table 4. The main steps prior to and during the sorting of packaging waste, and the reasons that they were performed by the participants.

\begin{tabular}{ccccc}
\hline & Always & Sometimes & Never & Main Reason \\
\hline Removing the cap or cutting the head & 30 & 6 & 1 & Preparing for emptying \\
Emptying the packaging & 30 & 6 & 1 & Preparing for cleaning \\
Cleaning the packaging & 22 & 9 & 6 & Preventing food odors \\
Folding/compacting & 32 & 4 & 1 & Saving space \\
Re-closing the cap & 28 & 7 & 2 & Preventing food odors and leaking \\
Separating the cap & 27 & 5 & 5 & Environmental concern \\
Sorting the cap as plastic and the & 27 & 5 & 5 & Environmental concern \\
body as a paperboard packaging & & & & \\
\hline
\end{tabular}

As can be seen from Table 4, most of the participants perceived that they had separated and sorted their packages. They usually performed the tasks sequentially from the top to the bottom row in Table 4. Comparison of the instructions for sorting with their actions listed in Table 4 showed that their 
actions are similar to the instructions of emptying, separating and sorting. The other steps, such as cleaning and folding, are not given in the instructions, but they are often a result of the participants' living conditions.

For example, cleaning with water and detergent wastes valuable water and chemicals, and such actions are not given in the instructions. However, these actions were performed by the participants to prevent the spreading of bad odors that would have resulted from the unused dairy product. In addition, compacting or folding the packages saved space in their kitchens.

"We live in a villa where we collect, sort, and keep the packaging waste in the garage and then transfer it to a recycling station once a week still, we fold the packaging waste to save a space."

These results are in agreement with those from previous studies, such as Bernstad [18], that showed that the lack of space at home could be a root cause for compacting the packaging waste. In addition, one of the participants compacted the waste, as it gave a sense of peace (see Figure 1).

"I am not into either recycling or sorting, yet finding new ways for folding packaging waste is rather fun and makes me calm."

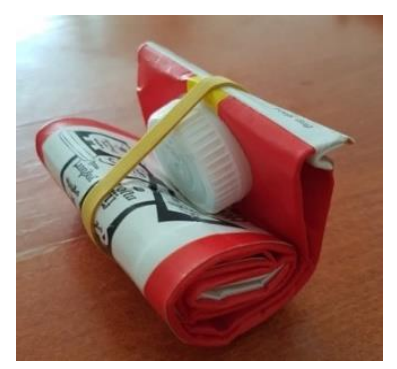

Figure 1. Illustration of a way of that a package was folded and kept compact by one of the participants.

Different graphical elements, such as logos, symbols, images and texts that can be perceived as relating to attitude, recycling and environmental knowledge, were discussed with the participants using questions Q4 and Q5. These are usually found on the packaging used in the study, and are shown in Figure 2. The discussion aimed to identify the way that the participants perceived these elements (e.g., if they were seen at all, and if they were perceived as giving useful information) and if some elements were more useful than others. The aims of these elements, which was retrieved from producers, are elaborated on in Appendix A [88-90]. Symbol-1 \& 2, Text-1 and 2, as well as Logo-1, 2 and 3, target attitude and environmental knowledge. Symbol-2, Image-1, and Text-2 are intended to enhance recycling knowledge, therefore motivating separation and sorting.

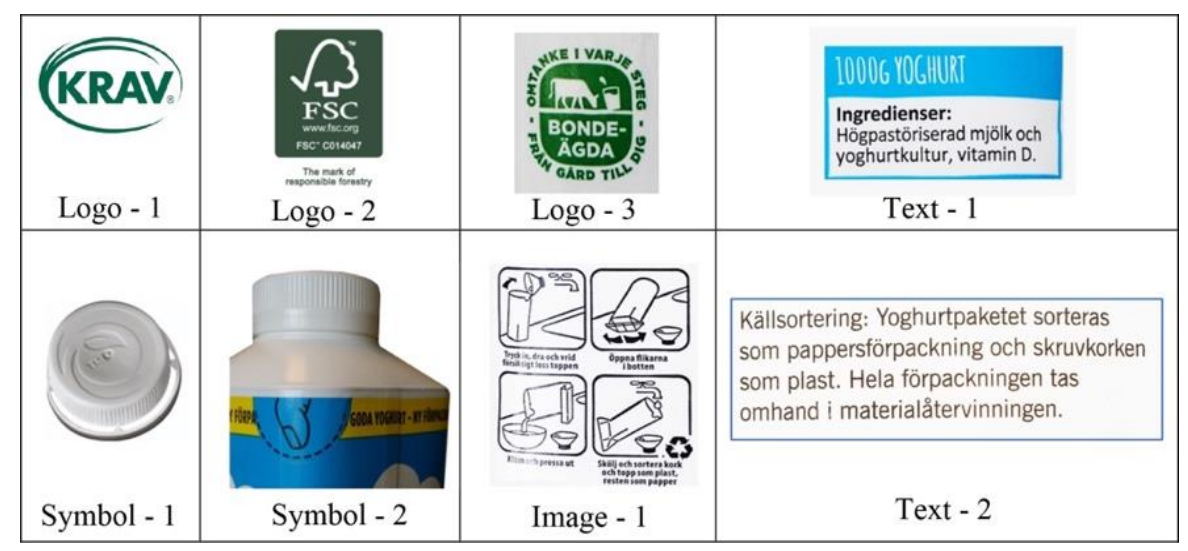

Figure 2. The logos, symbols, images and texts that are often found on the selected packaging, and that were discussed in the interviews. 
Table 5 lists the participants' statements about these graphical elements. The second column in the table presents statements that explain the participants' experiences. The third column, issues, describes the perceived problem with the element, i.e., that the element was not clear, or that the message was confusing. The final column shows how the elements were perceived by the participants, i.e., that they were inconvenient (difficult to read or not useful), or that it made the participants uncertain on how to separate and sort the packaging.

Table 5. The participants' statements regard to the packages' graphical elements.

\begin{tabular}{|c|c|c|c|}
\hline Elements & Participants' Statements & Issues & $\begin{array}{c}\text { Participants } \\
\text { Perception }\end{array}$ \\
\hline Logo-1 & I never noticed the logo (37 answers). & Not clear & Inconvenient \\
\hline 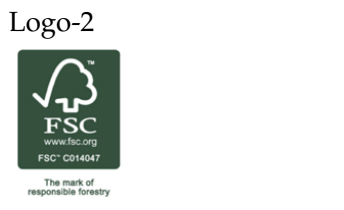 & $\begin{array}{l}\text { I did not see the logo ( } 35 \text { answers). } \\
\text { I saw the logo and it is related to environment issues } \\
\text { ( } 2 \text { answers). }\end{array}$ & Not clear & $\begin{array}{c}\text { Inconvenient } \\
\text { Uncertain }\end{array}$ \\
\hline 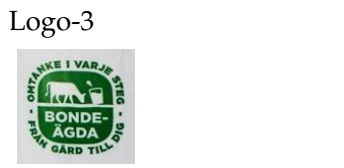 & $\begin{array}{l}\text { I never saw the logo ( } 36 \text { answers). } \\
\text { I saw the logo and it says that the content is natural milk } \\
\text { ( } 1 \text { answer). }\end{array}$ & $\begin{array}{l}\text { Not clear } \\
\text { - } \\
\text { Confusing }\end{array}$ & $\begin{array}{l}\text { Inconvenient } \\
\text { Uncertain }\end{array}$ \\
\hline Symbol- & I never saw the symbol (37 answers). & Not clear & Inconvenient \\
\hline $\begin{array}{l}\text { Text-2 } \\
\begin{array}{|l|}\text { Källsortering: Yoghurtpaketet sorteras } \\
\text { som pappersförpackning och skruvkorken } \\
\text { som plast. Hela förpackningen tas } \\
\text { omhand i materialătervinningen. }\end{array}\end{array}$ & $\begin{array}{l}\text { I did not know the information even existed ( } 8 \text { answers). } \\
\text { I saw the text but it's too small and not readable ( } 17 \text { answers). } \\
\text { I read it but it was confusing; even if the cap is separated from } \\
\text { the package there is still a plastic part inside the package that } \\
\text { the text doesn't explain how to take care of ( } 8 \text { answers). }\end{array}$ & $\begin{array}{l}\text { Not clear } \\
\quad- \\
\text { Confusing }\end{array}$ & $\begin{array}{l}\text { Inconvenient } \\
\text { Uncertain }\end{array}$ \\
\hline (1) & $\begin{array}{l}\text { I did not see the image ( } 30 \text { answers). } \\
\text { I saw the image but it is not related to recycling of the package } \\
\text { ( } 1 \text { answer). } \\
\text { I didn't notice the image, because I thought it might be } \\
\text { a cooking recipe ( } 2 \text { answers). } \\
\text { I saw the image, but the images are too small and not visible } \\
\text { ( } 4 \text { answers). }\end{array}$ & $\begin{array}{l}\text { Not clear } \\
- \\
\text { Confusing }\end{array}$ & $\begin{array}{l}\text { Inconvenient } \\
\text { Uncertain }\end{array}$ \\
\hline
\end{tabular}

In summary, the statements in Table 5 show that the visual elements are usually not clear, and that the messages that they are trying to communicate are confusing, even to those who seek this information. The different placements of data, logo and symbols on the packages, together with their 
small size, amplified the above situation, and was reported as the largest barrier for these elements to be a channel of communication with consumers. Thus, they were ignored by the participants. Figure 3 shows an example that was discussed in more detail above. The small size of the image does not catch the consumers' attention, and the text containing the sorting information was even smaller (in comparison with other verbal attributes). For this reason, participants were unable to read it, or mistook it for being a recipe.

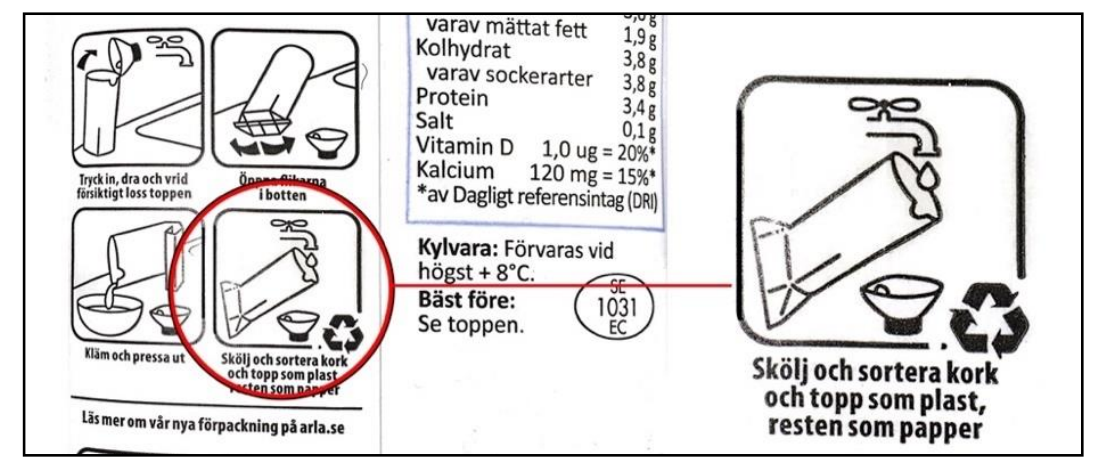

Figure 3. An illustration of the small size of the image and text that gives sorting information on a yogurt package. The scale of the main image (left) is 1:1 and is increased to 3:1 in the right image. The translation of the text under the symbol is: wash and sort the cap and top as plastic, and the rest as paper.

Table 5 shows that it is not only the text that the participants do not find useful, but also the symbols, logos and images. According to the participants' statements, the graphical elements should be designed to correspond with their intentions, and visual elements should be combined with verbal elements to give meaningful information. These properties are also suggested by other researchers, such as Carrillo et al. [91].

Showing the graphical elements to the participants also led to free discussion during the interviews. This yielded a deeper understanding of how these elements were perceived. The following are some explicit examples that arose from the participants' statements: Symbol-1 (see Figure 2) was carved on some packaging caps, and showed that the cap is made from biodegradable material (sugar cane). The symbol also indicates that there are lower carbon emissions when producing and recycling the cap [92,93]. In the absence of proper information, and the inability to communicate, the aim of the symbol was not understood. This is a disadvantage, since a previous study has shown that people are more likely to recycle if they are aware of the material's recyclability and the environmental benefits of recycling [94]. Also, some caps, even the larger ones, were not marked with a symbol. This disparity confused the participants, since it is not clear why some caps are marked, and others not.

Lack of clear information also caused uncertainty that impacted the participants' decision-making, especially during the cleaning and separation of the packaging waste. An example was the package with both a plastic cap and a plastic neck that was integrated with the paperboard carton. The producer recommendation, which is given on some of the packaging, is to "leave the packaging in the container for paper packaging and the loose screw cap in the plastic packaging container". This faced the participants with a dilemma If the cap should be removed and separated since it is plastic, then what would happen for the remaining plastic part (i.e., the neck)? If it does not need to be removed then why does the producer recommend that the cap be separated and sorted in a plastic container? Also, they were not sure to what extent packaging should be cleaned. Therefore, some participants cut the packaging to separate the plastic neck from the paper carton before washing both parts. Although this may be better sorting, it is time-consuming, and cannot be expected from all consumers. As expressed by most of the participants, although they want to sort, they can neglect to do so due to lack of time or the need for excessive effort, i.e., perceived inconvenience. 
The participants also stated that a reason for ignoring graphical elements is their placement on the package. The place that these elements appear also varied from one package to another. This lack of consistency in having the sorting information at the same place on the packaging, and even among different packages produced by the same company, was confusing, and made the participants reluctant to obtain the correct information. As can be seen in Figure 4, information on how to recycle the packaging is mentioned in different places and with different formats on the different packages, or not even mentioned at all.

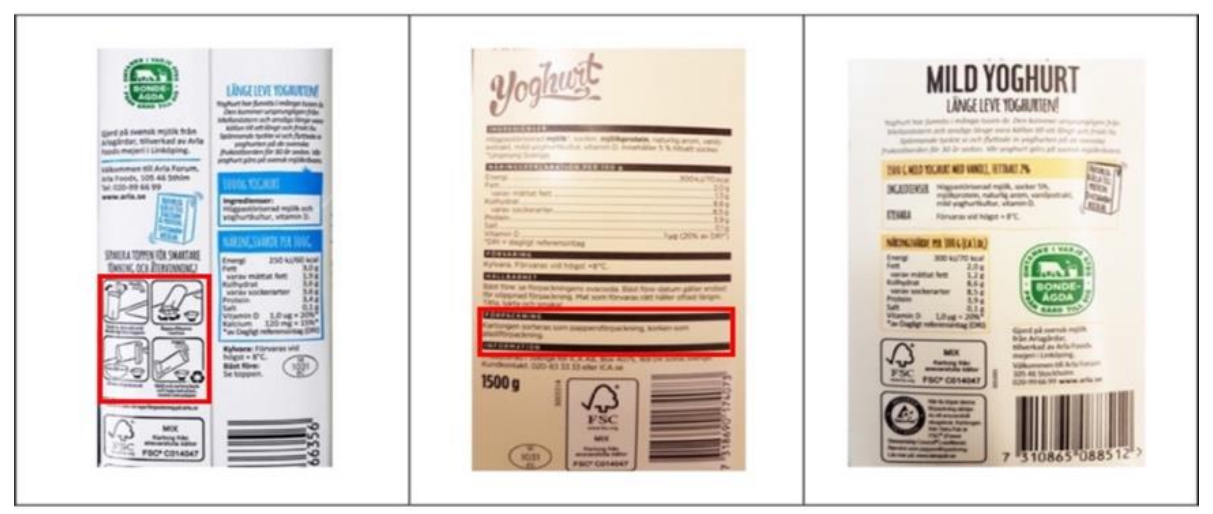

Figure 4. An example of where recycling information appears at different places (shown with red lines in the left and middle panels), and where this information is not given at all (right panel).

From a psychological perspective, this could be due to consumer desire to achieve a successful habitual performance, such as purchasing a product after having read its ingredients [95]. As marketing research has shown, consumers tend to search for desired information, such as ingredients, at the same place on all packaging [96]. Hence, proper arrangement of information, as well as giving it priority over other information on the package, whether it be text, logos, or symbols, could increase communication with consumers, which is also known as the hierarchy of information [97]. As previous research has shown, giving salient items a high priority on the packaging, by using, for example, visual elements, stimulates consumer attention [98]. This requires a delicate balance between visual and verbal attributes. Even small details may affect how consumers interpret the information, and can negatively affect consumer attitude. For example, using a small font for the sorting information may decrease the value of the information, giving it a lower priority to other information. As expressed by one of the participants: "It has always surprised me that this information is really important. Why do they write it in a smaller size compared to other information that is provided?" The main reason is that readers perceive a larger font as being more important [99]. Generally, selecting the right font size depends on certain variables, such as the purpose of the text, the place on packaging, the age of the main user, and the distance between the consumer and the package, whether it is on the shelf or in the consumer's hands. However, a size between 12pt-16pt appears to be large enough to be read by consumers. Also, black font on a white or light color background is widely known to be the best combination to enable reading $[96,100,101]$. In addition, it would be less confusing if different producers use the same terms for a specific purpose. For instance, Lidl, a company in Sweden, used the term 'sorting' (Källsortering in Swedish (sorting)) to guide consumer sorting of packaging while Arla used 'recycling' (Återvinn in Swedish (recycling)) for the same purpose.

The answers to the question about the importance of color combinations to simplify sorting (Q7) showed that most of the participants saw no benefit in using different colors for the main body of packaging. On the contrary, they thought that using vivid colors, e.g., red, for the cap, may remind them to separate and sort the cap separately. This implies that colors as visual attributes not only have a decorative character, but can also communicate a certain meaning, and can, therefore, be used to facilitate the way that consumers interpret a function. This has been noted in previous investigations [102]. 
Although the packaging was selected from different companies, and hence it differs in appearance (graphically), none of the packages were regarded as having a high quality due to their appearance. The participants had difficulty in using the term 'higher quality' (Q8) to distinguish between the packages themselves, but rather used it to refer to the contents. This is not consistent with previous results, that found that the packaging design can affect the perception of the quality of the packaging, e.g., $[27,103,104]$. Instead of discussing 'quality', the participants preferred to use the term 'higher value' to distinguish between the packages. Within this study, the larger packages and those that had better functionality during use were considered as having a higher value.

This might be due to weak graphic design, or manifesting the low effect of appearance on perceiving quality in the product that is purchased and used habitually.

There was no consensus regarding the influence of different sizes on sorting behavior (Q9). As stated earlier, bigger packaging has been seen as an obstacle for proper sorting. However, at least for the range of sizes used in the present study, contradictory results were obtained, since the smallest package (300 cc) was perceived to be the most problematic to sort. This was due to the difficulty of folding the small packaging at the same time that it was perceived to have a low value. It was, therefore, more likely to be discarded in the mixed-waste fraction. Similarly, several participants perceived that the biggest package (1500 cc) had the highest value, since it contained more paperboard, and this package was sorted correctly.

In the last question $(\mathrm{Q} 10)$ the participants were asked to share their experiences regarding the suitability and ease of sorting the different packages. This part of the interview was primarily conducted using free discussions, and identified the participants' suggestions to improve the packaging to make it more suitable for sorting. Table 6 lists these suggestions and what the participants perceived as advantageous or disadvantageous for the proper sorting of each type of packaging waste.

Table 6. Participants' experiences in sorting the different types of packaging.

\begin{tabular}{|c|c|c|}
\hline Product & Participants' Experiences & $\begin{array}{l}\text { Participants' } \\
\text { Perceptions }\end{array}$ \\
\hline $\begin{array}{l}\text { Type A } \\
\text { Yogurt } \\
1000 \mathrm{~g}\end{array}$ & $\begin{array}{l}\text { - I like the way that it is made from paper and that it has a wide-open mouth for emptying } \\
\text { and washing. In addition, you can check the remaining contents all the time! } \\
\text { - } \\
\text { It's easy to open, use, empty and clean! We used to have this type of package when I was } \\
\text { a kid. } \\
\text { - } \\
\text { Its open mouth lets you to clean it easily and you can even use your hands. It has no } \\
\text { plastic parts. } \\
\text { It's easy to empty and clean, although its sticky upper edges require too much effort to clean. } \\
\text { - } \quad \text { It's easy to use and recycle since it's made from pure cardboard. } \\
\text { - } \quad \text { From the moment that you open it, you have to take care that its mouth edges are clean, } \\
\text { otherwise you can't close the mouth and it is hard to wash out the yogurt later on when } \\
\text { it dries. } \\
\text { I don't like it at all; you can't re-close the mouth the content gets a fridge smell and spoils } \\
\text { much faster than the contents in the other packages that have a cap. However, it's really } \\
\text { easy for recycling! }\end{array}$ & $\begin{array}{l}\text { Convenient for } \\
\text { separating and sorting }\end{array}$ \\
\hline $\begin{array}{l}\text { Type B } \\
\text { Yogurt } \\
1000 \mathrm{~g}\end{array}$ & $\begin{array}{l}\text { - } \\
\text { - I never remove the cap before sorting to prevent spreading of a bad smell in my kitchen. } \\
\text { integrated with body. } \\
\text { - } \quad \text { Even in the recycling instruction it's not clear what you have to do with the integrated } \\
\text { plastic part before sorting! } \\
\text { - It's easy for separating and sorting, since it just made from paper and plastic. } \\
\text { - You can pour water and soap into it and then closed the cap and shake the package, then } \\
\text { pouring out the whole content is easy! } \\
\text { - } \\
\text { Its cubic form with sharp edges makes it difficult to clean since the yogurt sticks to these } \\
\text { how it could be better! } \\
\text { Its size perfectly matches with your fridge and because of its cap you can fold it and keep it } \\
\text { in minimum size which suits me since I empty my trash bin less than once a week! }\end{array}$ & $\begin{array}{l}\text { Somewhat inconvenient } \\
\text { for separating and } \\
\text { sorting } \\
\text { High value } \\
\text { Uncertain how to } \\
\text { separate and sort }\end{array}$ \\
\hline
\end{tabular}


Table 6. Cont.

\begin{tabular}{|c|c|c|}
\hline Product & Participants' Experiences & $\begin{array}{l}\text { Participants' } \\
\text { Perceptions }\end{array}$ \\
\hline $\begin{array}{l}\text { Type C } \\
\text { Yogurt } \\
1000 \mathrm{~g}\end{array}$ & $\begin{array}{l}\text { - } \quad \text { Its straight and wide mouth makes it easy to empty and wash with water. } \\
\text { - You can see if there is any leftover yogurt which also doesn't stick inside since the corners } \\
\text { are curved. } \\
\text { - } \quad \text { I prefer the usual one (cubic and sharp edge) since its form, material and curved edges make } \\
\text { it slippery, especially when you want to wash it, and in general I feel uncomfortable! } \\
\text { Its cap can be removed easily, but it is a struggle to detach the plastic part on head from the } \\
\text { main body. } \\
\text { - It's not easy to fold. In fact, you have to spend time to open the lower edges to be able to } \\
\text { fold it after the plastic part is cut and removed, or, as I do; you can crumple it! } \\
\text { - } \quad \text { Its curved edges and big plastic part doesn't allow me to fold it, and it therefore occupied } \\
\text { a big space in my little trash bin. } \\
\text { Up until now I have sorted it as plastic waste. Because of its form and graphic I didn't } \\
\text { realize that it was made from paper! }\end{array}$ & $\begin{array}{l}\text { Somewhat inconvenient } \\
\text { for separating and } \\
\text { sorting } \\
\text { High value } \\
\text { Uncertain how to } \\
\text { separate and sort }\end{array}$ \\
\hline $\begin{array}{l}\text { Type D } \\
\text { Yogurt } \\
1500 \mathrm{~g}\end{array}$ & $\begin{array}{l}\text { - The bigger size means more leftover yogurt if you don't consume it before the proper time, } \\
\text { and then it's not easy to empty and clean since you need a lot of water to get rid of } \\
\text { the yogurt! } \\
\text { - You need a steady hand, and probably both hands, to make it completely empty and to } \\
\text { wash it. } \\
\text { - } \quad \text { Its small entrance makes it difficult to empty and clean compared with the smaller size. } \\
\text { - } \quad \text { I can't fold it since needs a lot of effort, and therefore I usually throw it away without folding. } \\
\text { - } \quad \text { Even if it's not easy to clean and wash I never leave this package in the mixed waste since } \\
\text { they made it from a huge amount of paper! } \\
\text { - I don't have enough space for a big package like this so I try to avoid purchasing packages } \\
\text { of this size as much as possible. } \\
\text { Since it's a big paper package with a small cap and an integrated plastic part, I didn't } \\
\text { remove the cap because I cannot see how this makes any difference in the end! }\end{array}$ & $\begin{array}{l}\text { Inconvenient for } \\
\text { separating and sorting } \\
\text { High value } \\
\text { Uncertain how to } \\
\text { separate and sort }\end{array}$ \\
\hline $\begin{array}{l}\text { Type E } \\
\text { Cream } \\
500 \mathrm{~g}\end{array}$ & $\begin{array}{l}\text { Its small size and big cap make it really easy to empty and clean. } \\
\text { I don't fold it since it is too small and its curved edge and big plastic head makes it difficult to fold. } \\
\text { If I have time I'll cut the plastic part, otherwise I leave it un-touched in the package waste. } \\
\text { It's really confusing; they wrote to separate the plastic cap but they didn't mention why a small } \\
\text { package like this has a big plastic part at the head. Also, how should it be separated from } \\
\text { the body? } \\
\text { I don't like this package; it's small, but it has a big plastic part that it's not good for } \\
\text { the environment. }\end{array}$ & $\begin{array}{l}\text { Somewhat inconvenient } \\
\text { for separating and } \\
\text { sorting } \\
\text { Uncertain how to } \\
\text { separate and sort }\end{array}$ \\
\hline $\begin{array}{l}\text { Type F } \\
\text { Cream } \\
300 \mathrm{~g}\end{array}$ & $\begin{array}{l}\text { Actually, it's so small that sometimes I didn't wash it, and then I needed to keep the cap on to } \\
\text { prevent spreading of a bad smell. } \\
\text { Its small size doesn't make it worth to fold it! } \\
\text { A small amount of water is enough to clean it. } \\
\text { Sometimes I sort it in packaging bins without removing the cap because I can't remove the whole } \\
\text { plastic part. } \\
\text { I don't fold it because this is not easy for a package of this size, but its cubic form reminds me not } \\
\text { to sort it as mixed waste. }\end{array}$ & $\begin{array}{l}\text { Somewhat inconvenient } \\
\text { for separating and } \\
\text { sorting } \\
\text { Uncertain how to } \\
\text { separate and sort }\end{array}$ \\
\hline
\end{tabular}

The statements in Table 6 reveal that consumers may be hindered from sorting packaging properly if the design of the packaging is not consistent with consumer needs. One inconsistency is when the packaging attributes do not support functions that enhance proper sorting. For example, packages with rounded corners and a plastic neck (Type $C$ and E) are perceived to be easier to empty and clean in comparison with cubic packaging with sharper edges, but at the same time, they make separation and sorting more difficult. In this case, the neck was difficult to detach from the paperboard carton (the rounded corners also made it harder to grip the package when removing the neck). Thus, instead of struggling to separate and fold the package, as instructed on the package (see Figure 3), the participants often preferred to use water to empty the package before sorting as paperboard waste, without separating the plastic neck. Additionally, some participants incorrectly sorted the packaging as plastic waste, since the shiny white color used for both the plastic neck and paperboard carton gave the impression that the entire package was made from plastic. Another inconsistency was found between the function of the packaging to preserve its content and its function to enhance sorting. For example, one of the packages (Type A) has no plastic parts, and its mouth can be completely opened, making it easy to empty and fold. This enhances proper sorting, but the inability to re-close the package makes it difficult to keep the contents fresh. 
A possible explanation for these inconsistencies is that some of the packaging functions and features have been defined in general terms, without considering the needs of consumers, whether during usage or sorting. Based on psychological studies, repeatedly performing a behavior, such as sorting waste after use, must be convenient and easy to perform automatically $[105,106]$. Hence, inconsistencies in the design of packaging identified here may negatively impact consumer interaction with the package, and negatively influence consumer behavior during waste sorting (lack of satisfaction). This research finding is not in line with the manufacturer's desire to seek customer support for increased recycling rates [107].

In the present study, the waste sorting process was guided more by the participants' attitudes and their relatively high recycling knowledge, than by the packaging features. Participants' statements often illustrated the same behavior, irrespective of whether the packaging had special functions that facilitated the sorting process (e.g., ease of emptying or separating) or not. This is because these special functions were not noticed nor discovered by the participants (lack of usability). The selected packages, therefore, have been able to fulfill their primary function as containers, but, except the recyclable materials used to make the packages (paperboard bodies), they have no features that successfully guide waste sorting. Thus, they have failed to meet consumer expectations about usability and satisfaction during waste sorting. A proper design [48], therefore, is needed to bring the potential to sort packaging to the attention of consumers and to make it understandable. Proper design is also crucial for extended producer responsibility, which is required by the European Commission [108], and commits the producer to reduce the environmental impact of products and services throughout the product's lifecycle, including separation and sorting [109].

This can be achieved by (1) selecting meaningful visual attributes, for example, ascertaining where the packaging should be folded, either by using a dotted or perforation line, and (2) providing declarative and oriented information about waste sorting that is aligned with consumer needs; for example, how and to what extent packaging should be cleaned.

Also, to stimulate consumer sorting behavior, information may be needed about the necessity of separating and sorting food packaging waste, and the consequences of neglecting these tasks. Present information on selected packages is often limited to clarifying where consumers are expected to sort the separated waste.

\section{Conclusions}

Proper design of food packaging has the potential to enhance consumer decision-making when separating and sorting packaging waste. Current food packaging does not seem to communicate this information adequately, and appears to be designed as a container before and during the consumption of the contents, rather than a facilitator for separating and sorting the packaging after the contents are consumed. Improving the ability of the packaging to guide sorting may be more important for consumable products that are purchased often, such as yogurt and cream, and that are sorted habitually. This type of food packaging should be able to communicate relevant information to the consumer. This can be done by giving attention to its functions, form, texture, color and usability, and by selecting recyclable materials that can easily be separated from each other. This may be as important as advancing manufacturing and recycling technology. Furthermore, the information about separation and sorting must be easy to find and understandable to consumers.

It appears that the use of packaging as a source of information to support the separation and sorting of the packaging waste has not received the same attention as improving the packaging fabrication and selecting recyclable materials. However, this study reveals that choosing recyclable materials does not guarantee the proper separation and sorting of the packaging. In fact, it was seen that there are many other factors that need to be taken into account, such as consistency between the form of the package with its functions. Along with this, waste separation and sorting are often rituals to fulfill citizens' duties, and are often done routinely as a habit. The process must, therefore, 
be easy and convenient for consumers. Hence, packaging functions, such as ease of emptying, cleaning, separating and folding, are most likely features that can be used to enhance proper sorting.

Considering the package as a product, with and without its contents, will expand its current domain of responsibility, and reveal abilities that have not previously been investigated. In particular, sustainable waste management would benefit if there was more knowledge and data available about the influence of specific packaging attributes on consumer behavior. Further research is needed to understand how the appearance of food packages, such as shape, texture, color and packaging characteristics, can be used to improve waste sorting. In addition, the habitual essence of waste sorting identifies a need for more specific packaging research that can provide empirical data for improving the design of the packaging.

Author Contributions: Conceptualization, B.N.; Methodology, B.N., K.R.; Validation, B.N., K.R., K.B., and M.R.; Formal Analysis, B.N.; Investigation, B.N.; Data Curation, B.N.; Writing-Original Draft Preparation, B.N.; Writing-Review and Editing, B.N., K.R., K.B. and M.R.; Supervision, K.R. All authors have read and agreed to the published version of the manuscript.

Funding: The research was funded by Sparbankstiftelsen Sjuhärd.

Acknowledgments: The authors are grateful for the financial support from Sparbankstiftelsen Sjuhärd.

Conflicts of Interest: The authors declare no conflict of interest.

\section{Appendix A}

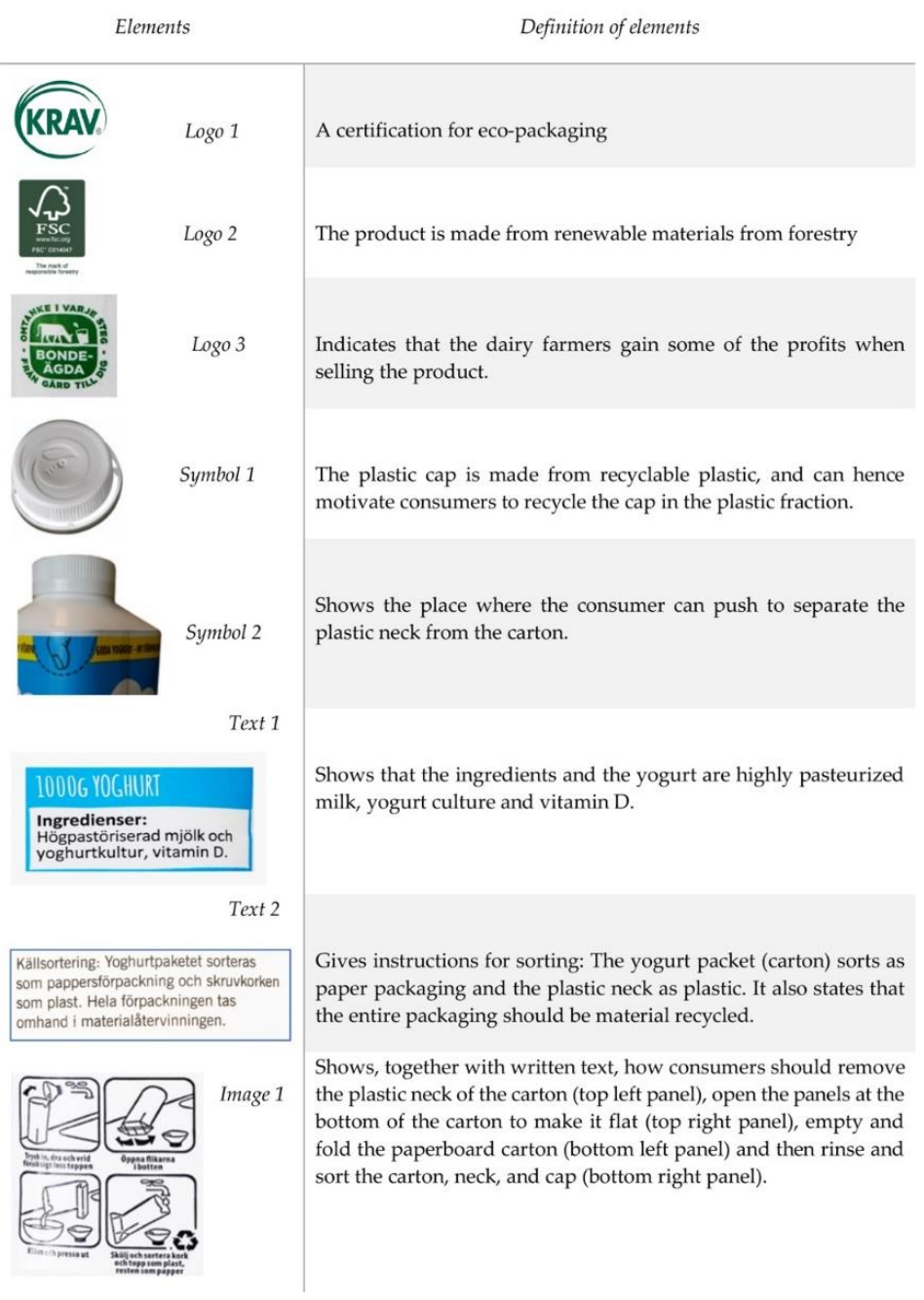

Figure A1. Definition of logos, symbols, images, and texts that are often found on the selected packaging and that were discussed in the interviews provided in Figure 2. 


\section{References}

1. Hoornweg, D.; Bhada-Tata, P. What a Waste: A Global Review of Solid Waste Management; World Bank: Washington, DC, USA, 2012.

2. Tchobanoglous, G.; Theisen, H.; Vigil, S.A. Integrated Solid Waste Management: Engineering Principles and Management Issues; McGraw-Hill: New York, NY, USA, 1993.

3. Wohner, B.; Pauer, E.; Heinrich, V.; Tacker, M. Packaging-Related Food Losses and Waste: An Overview of Drivers and Issues. Sustainability 2019, 11, 264. [CrossRef]

4. US EPA. Containers and Packaging: Product-Specific Data; United States Environmental Protection Agency: Washington, DC, USA, 2019.

5. Eurostat. Packaging Waste Statistics—Statistics Explained. Available online: https://ec.europa.eu/eurostat/ statistics-explained/index.php/Packaging_waste_statistics (accessed on 21 June 2019).

6. AvfallSverige. Position Paper on Plastics-Avfall Sverige; Avfall Sverige: Malmö, Sweden, 2018.

7. Plastemart. Food Packaging Accounts for Almost 35\% of the Global Packaging Market. Available online: http://www.plastemart.com/plastic-technical-articles/food-packaging-accounts-for-almost-35-ofthe-global-packaging-market/2337 (accessed on 9 January 2019).

8. Tencati, A.; Pogutz, S.; Moda, B.; Brambilla, M.; Cacia, C. Prevention Policies Addressing Packaging and Packaging Waste: Some Emerging Trends. Waste Manag. 2016, 56, 35-45. [CrossRef] [PubMed]

9. The guardian. Throwaway Culture Has Spread Packaging Waste Worldwide|Waste packaging|Environment|The Guardian. Available online: https:/www.theguardian.com/environment/2017/ mar/13/waste-plastic-food-packaging-recycling-throwaway-culture-dave-hall (accessed on 21 June 2019).

10. Ryan, V. The Functions of Packaging. Available online: http://www.technologystudent.com/despro2/packfn1. htm (accessed on 27 November 2019).

11. Chrzan, J. Nearly Sixty Percent of All Printed Packaging Is Food|Packaging World. Available online: https://www.packworld.com/design/package-design/article/13375688/nearly-sixty-percent-of-allprinted-packaging-is-food (accessed on 27 November 2019).

12. Eriksen, M.; Lebreton, L.C.; Carson, H.S.; Thiel, M.; Moore, C.J.; Borerro, J.C.; Galgani, F.; Ryan, P.G.; Reisser, J. Plastic pollution in the world's oceans: More than 5 trillion plastic pieces weighing over 250,000 tons afloat at sea. PLoS ONE 2014, 9, e111913. [CrossRef] [PubMed]

13. Ribble. Fifteen Plastic Packaging Statistics That Will Scare You • Ribble. Available online: https://ribble-pack. co.uk/environment/plastic-packaging-statistics (accessed on 27 November 2019).

14. Avfall. Sweden Waste Plan for 2017-2020. Available online: https://www.stockholmvattenochavfall.se/ globalassets/pdf1/riktlinjer/avfall/avfallsplan/sva072-avfallsplan_en.pdf (accessed on 16 January 2020).

15. Pizarro, I.O. Turning Waste into Resources: Rethinking the Way We Discard Things; Chalmers University: Göteborg, Sweden, 2014.

16. Rousta, K.; Richards, T.; Taherzadeh, M.J. An Overview of Solid Waste Management toward Zero Landfill: A Swedish Model. In Resource Recovery to Approach Zero Municipal Waste; CRC Press: Boca Raton, FL, USA, 2015; pp. 1-22.

17. Rousta, K.; Dahlén, L. Source Separation of Household Waste: Technology and Social Aspects. In Resource Recovery to Approach Zero Municipal Waste; CRC Press: Boca Raton, FL, USA, 2015; pp. 61-76. [CrossRef]

18. Bernstad, A. Household Food Waste Separation Behavior and the Importance of Convenience. Waste Manag. 2014, 34, 1317-1323. [CrossRef]

19. Zain, S.M.; Basri, N.E.A.; Basri, H.; Zakaria, N.; Elfithri, R.; Ahmad, M.; Ghee, T.K.; Shahudin, Z.; Yaakub, S.; Khan, I.A.I. Focusing on Recycling Practice to Promote Sustainable Behavior. Procedia Soc. Behav. Sci. 2012, 60, 546-555. [CrossRef]

20. Fti. About FTI - Förpacknings- och tidningsinsamlingen, FTI. Available online: https://www.ftiab.se/1492.html (accessed on 22 February 2020).

21. AvfallSverige. Swedish Waste Management; Avfall Sverige: Malmö, Sweden, 2018.

22. Rousta, K.; Ekström, K. Assessing Incorrect Household Waste Sorting in a Medium-Sized Swedish City. Sustainability 2013, 5, 4349-4361. [CrossRef]

23. Vyas, H. Packaging Design Elements \& Users Perception Packaging Design Elements and Users Perception: A Context in Fashion Branding and Communication. J. Appl. Packag. Res. 2015, 7, 5. 
24. Azzi, A.; Battini, D.; Persona, A.; Sgarbossa, F. Packaging Design: General Framework and Research Agenda. Packag. Technol. Sci. 2012, 25, 435-456. [CrossRef]

25. Wikström, F.; Williams, H.; Verghese, K.; Clune, S. The Influence of Packaging Attributes on Consumer Behaviour in Food-Packaging Life Cycle Assessment Studies-A Neglected Topic. J. Clean. Prod. 2014, 73, 100-108. [CrossRef]

26. Wikström, F.; Williams, H.; Venkatesh, G. The Influence of Packaging Attributes on Recycling and Food Waste Behaviour-An Environmental Comparison of Two Packaging Alternatives. J. Clean. Prod. 2016, 137, 895-902. [CrossRef]

27. van Ooijen, I.; Fransen, M.L.; Verlegh, P.W.J.; Smit, E.G. Packaging Design as an Implicit Communicator: Effects on Product Quality Inferences in the Presence of Explicit Quality Cues. Food Qual. Prefer. 2017, 62, 71-79. [CrossRef]

28. Jelsma, J. Designing 'Moralized' Products. In User Behavior and Technology Development; Springer: Berlin/Heidelberg, Germany, 2006; pp. 221-231. [CrossRef]

29. Plumb, A.; Downing, P.; Consulting, I.; Andrew, P. Consumer Attitudes to Food Waste and Food Packaging: Summary of Research Findings; Waste \& resources action programme: Barbury, UK, 2012; Available online: https://www.wrap.org.uk (accessed on 9 March 2020).

30. Silvenius, F.; Grönman, K.; Katajajuuri, J.-M.; Soukka, R.; Koivupuro, H.-K.; Virtanen, Y. The Role of Household Food Waste in Comparing Environmental Impacts of Packaging Alternatives. Packag. Technol. Sci. 2014, 27, 277-292. [CrossRef]

31. Lindh, H.; Williams, H.; Olsson, A.; Wikström, F. Elucidating the Indirect Contributions of Packaging to Sustainable Development: A Terminology of Packaging Functions and Features. Packag. Technol. Sci. 2016, 29, 225-246. [CrossRef]

32. Wikström, F.; Verghese, K.; Auras, R.; Olsson, A.; Williams, H.; Wever, R.; Grönman, K.; Kvalvåg Pettersen, M.; Møller, H.; Soukka, R. Packaging Strategies That Save Food: A Research Agenda for 2030. J. Ind. Ecol. 2018. [CrossRef]

33. Henriksson, G.; Åkesson, L.; Ewert, S. Uncertainty Regarding Waste Handling in Everyday Life. Sustainability 2010, 2, 2799-2813. [CrossRef]

34. Langley, J.; Turner, N.; Yoxall, A. Attributes of Packaging and Influences on Waste. Packag. Technol. Sci. 2011, 24, 161-175. [CrossRef]

35. Wever, R.; van Onselen, L.; Silvester, S.; Boks, C. Influence of Packaging Design on Littering and Waste Behaviour. Packag. Technol. Sci. 2010, 23. [CrossRef]

36. Williams, H.; Wikström, F.; Wetter-Edman, K.; Kristensson, P. Decisions on Recycling or Waste: How Packaging Functions Affect the Fate of Used Packaging in Selected Swedish Households. Sustainability 2018, 10, 4794. [CrossRef]

37. Williams, H.; Wikström, F.; Otterbring, T.; Löfgren, M.; Gustafsson, A. Reasons for Household Food Waste with Special Attention to Packaging. J. Clean. Prod. 2012, 24, 141-148. [CrossRef]

38. Froome, C.; Buelow, S.; Lewis, H.; Sonneveld, K. The Role of Labels in Directing Consumer Packaging Waste. Manag. Environ. Qual. An Int. J. 2010, 21, 198-213.

39. Scott, L.; Vigar-Ellis, D. Consumer Understanding, Perceptions and Behaviours with Regard to Environmentally Friendly Packaging in a Developing Nation. Int. J. Consum. Stud. 2014, 38, 642-649. [CrossRef]

40. Wilson, N.L.W.W.; Rickard, B.J.; Saputo, R.; Ho, S.-T. Food Waste: The Role of Date Labels, Package Size, and Product Category. Food Qual. Prefer. 2017, 55, 35-44. [CrossRef]

41. Strydom, W. Barriers to Household Waste Recycling: Empirical Evidence from South Africa. Recycling 2018, 3, 41. [CrossRef]

42. Chen, F.; Chen, H.; Yang, J.; Long, R.; Li, W. Impact of Regulatory Focus on Express Packaging Waste Recycling Behavior: Moderating Role of Psychological Empowerment Perception. Environ. Sci. Pollut. Res. 2019, 26, 8862-8874. [CrossRef] [PubMed]

43. Ordoñez, I.; Harder, R.; Nikitas, A.; Rahe, U. Waste Sorting in Apartments: Integrating the Perspective of the User. J. Clean. Prod. 2015, 106, 669-679. [CrossRef]

44. Wikström, F.; Williams, H.; Trischler, J.; Rowe, Z. The Importance of Packaging Functions for Food Waste of Different Products in Households. Sustainability 2019, 11, 2641. [CrossRef] 
45. Marc. 95 Percent of Brain Activity Is beyond Our Conscious Awareness|Neurosciences UX. Available online: http://www.simplifyinginterfaces.com/2008/08/01/95-percent-of-brain-activity-is-beyondour-conscious-awareness/ (accessed on 17 February 2020).

46. Kluger, J. Consciousness: It's Less Than You Think|Time. Available online: https://time.com/3937351/ consciousness-unconsciousness-brain/ (accessed on 14 February 2020).

47. Bloch, P.H. Seeking the Ideal Form: Product Design and Consumer Response. J. Mark. 1995, 59, 16. [CrossRef]

48. Ashby, M.; Johnson, K. The Art of Materials Selection. In Materials Today; Elsevier: Amsterdam, The Netherlands, 2003; pp. 24-35. [CrossRef]

49. Kamil, M.J.M.; Abidin, S.Z. Unconscious Human Behavior at Visceral Level of Emotional Design. Procedia Soc. Behav. Sci. 2013, 105, 149-161. [CrossRef]

50. Pettersson, J. Coca-Cola in Sweden Will Be the First to “Order Me again" Labels-Packnews.se Your Packaging Magazine Online-Pack News, Packaging, Packaging, Packaging. Available online: https: //www.packnews.se/coca-cola-i-sverige-blir-forst-med-panta-mig-igen-etiketter/ (accessed on 17 February 2020).

51. Cox, C. Psychology of Recycling: Driving Consumer Recycling Behavior. Available online: https:// sustainablepackaging.org/psychology-recycling-driving-consumer-recycling-behavior/ (accessed on 12 September 2018).

52. Zhang, H.; Wen, Z.-G. Residents' Household Solid Waste (HSW) Source Separation Activity. Sustainability 2014, 6, 6446-6466. [CrossRef]

53. Rousta, K.; Bolton, K.; Dahlén, L. A Procedure to Transform Recycling Behavior for Source Separation of Household Waste. Recycling 2016, 1, 147-165. [CrossRef]

54. Nemat, B.; Razzaghi, M.; Bolton, K.; Rousta, K. The Role of Food Packaging Design in Consumer Recycling Behavior-A Literature Review. Sustainability 2019, 11, 4350. [CrossRef]

55. Ajzen, I.; Fishbein, M. Understanding Attitudes and Predicting Social Behavior; Prentice-Hall: Upper suderliver, NJ, USA, 1980.

56. Ajzen, I. The Theory of Planned Behavior. Organ. Behav. Hum. Decis. Process. 1991, 50, 179-211. [CrossRef]

57. S, B.; AB, A. Consumers Attitude and Behavior Towards Domestic Waste Recycling in Developing Countries: A Case Study. Adv. Recycl. Waste Manag. 2017, 2, 1-8. [CrossRef]

58. Wright, Y.L. Relating recycling: Demographics, attitudes, knowledge and recycling behavior among UC Berkeley students. UC Berkeley Stud. Recycl. 2011. Available online: https://pdfs.semanticscholar.org/a518/ 48437a096ddf0261b81866be1b00ea018b5d.pdf (accessed on 9 March 2020).

59. Humphrey, C.R.; Bord, R.J.; Hammond, M.M.; Mann, S.H. Attitudes and Conditions for Cooperation in a Paper Recycling Program. Environ. Behav. 1977, 9, 107-124. [CrossRef]

60. Xu, D.Y.; Lin, Z.Y.; Gordon, M.P.R.; Robinson, N.K.L.; Harder, M.K. Perceived Key Elements of a Successful Residential Food Waste Sorting Program in Urban Apartments: Stakeholder Views. J. Clean. Prod. 2016, 134, 362-370. [CrossRef]

61. Srun, P.; Kurisu, K. Internal and External Influential Factors on Waste Disposal Behavior in Public Open Spaces in Phnom Penh, Cambodia. Sustainability 2019, 11, 1518. [CrossRef]

62. Barr, S. Household Waste in Social Perspective: Values, Attitudes, Situation, and Behaviour; Routledge: London, UK, 2002.

63. Lindh, H.; Olsson, A.; Williams, H. Consumer Perceptions of Food Packaging: Contributing to or Counteracting Environmentally Sustainable Development? Packag. Technol. Sci. 2015, 29, 3-23. [CrossRef]

64. Lewis, K.V.H.; Fitzpatrick, L.; Verghese, K.; Lewis, H.; Fitzpatrick, L. Packaging for Sustainability; Verghese, K., Verghese, K., Lewis, H., Fitzpatrick, L., Eds.; Springer: London, UK, 2012. [CrossRef]

65. Silayoi, P.; Speece, M. The Importance of Packaging Attributes: A Conjoint Analysis Approach. Eur. J. Mark. 2007, 41, 1495-1517. [CrossRef]

66. Krishna, A.; Cian, L.; Aydınoğlu, N.Z. Sensory Aspects of Package Design. J. Retail. 2017, 93, 43-54. [CrossRef]

67. Magnier, L.; Schoormans, J. Consumer Reactions to Sustainable Packaging: The Interplay of Visual Appearance, Verbal Claim and Environmental Concern. J. Environ. Psychol. 2015, 44, 53-62. [CrossRef]

68. Townsend, J.D.; Kang, W.; Montoya, M.M.; Calantone, R.J. Brand-Specific Design Effects: Form and Function. J. Prod. Innov. Manag. 2013, 30, 994-1008. [CrossRef] 
69. Trudel, R.; Argo, J.J. The Effect of Product Size and Form Distortion on Consumer Recycling Behavior. J. Consum. Res. 2013, 40, 632-643. [CrossRef]

70. Trudel, R.; Argo, J.J.; Meng, M.D. Trash or Recycle? How Product Distortion Leads to Categorization Error During Disposal. Environ. Behav. 2016, 48, 966-985. [CrossRef]

71. Mutsikiwa, M.; Marumbwa, J. The Impact of Aesthetics Package Design Elements on Consumer Purchase Decisions: A Case of Locally Produced Dairy Products in Southern Zimbabwe. IOSR J. Bus. Manag. 2013, 8, 64-71. [CrossRef]

72. Spence, C. Multisensory Packaging Design: Color, Shape, Texture, Sound, and Smell. In Integrating the Packaging and Product Experience in Food and Beverages: A Road-Map to Consumer Satisfaction; Woodhead Publishing: Cambridge, UK, 2016. [CrossRef]

73. Proto.io. How Form and Function Play into the Rise of Good Design. Available online: https://medium. theuxblog.com/how-form-and-function-play-into-the-rise-of-good-design-88503c206f97 (accessed on 24 December 2018).

74. Johansson, K. Understanding Recycling Behavior: A Study of Motivational Factors behind Waste Recycling. In WIT Transactions on Ecology and the Environment; WIT Press: Ashurst, UK, 2016; Volume 202, pp. 401-414. [CrossRef]

75. Kollmuss, A.; Agyeman, J. Mind the Gap: Why Do People Act Environmentally and What Are the Barriers to pro-Environmental Behavior? Environ. Educ. Res. 2002, 8, 239-260. [CrossRef]

76. IDEO Design Kit. Available online: https://www.designkit.org/human-centered-design (accessed on 23 January 2020).

77. Dalberg. What is Human-Centered Design?|Dalberg. Available online: https://www.dalberg.com/whathuman-centered-design (accessed on 23 January 2020).

78. Ulrich, K. Product Design and Development, 5th ed.; McGraw-Hill/Irwin: New York, NY, USA, 2012.

79. VanderStoep, S.W.; Johnston, D.D. Research Methods for Everyday Life: Blending Qualitative and Quantitative Approaches; Jossey-Bass: San Francisco, CA, USA, 2009.

80. Qu, S.; Dumay, J. The Qualitative Research Interview. Qual. Res. Account. Manag. 2011. [CrossRef]

81. LRF Lantbrukarnas Riksförbund. Available online: https://www.lrf.se/ (accessed on 6 January 2019).

82. Blunt Leah. Recycling Mystery: Milk and Juice Cartons|Earth911.com. Available online: https://earth911. com/home-garden/recycling-mystery-milk-and-juice-cartons/ (accessed on 19 December 2018).

83. Pira. The Future of Packaging Industry: Paper and Board|Smithers Pira. Available online: https://www. smitherspira.com/resources/2018/february/the-future-of-packaging-trends (accessed on 1 August 2019).

84. Stenarecycling. Återvinning och avfallshantering i Karlskrona|Stena Recycling. Available online: https: //www.stenarecycling.se/hitta-till-oss/karlskrona/karlskrona/ (accessed on 15 February 2020).

85. TRT Swedish Recycling so Successful It Is Importing Rubbish. Available online: https://www.trtworld.com/ europe/swedish-recycling-so-successful-it-is-importing-rubbish-24491 (accessed on 13 October 2019).

86. Avffarsverken. The Right Waste in the Right Bin; Avffarsverken: Stockholm, Sweden, 2016. Available online: https://www.Affarsverken.se/sortera (accessed on 9 March 2020).

87. Fråne, A.; Stenmarck, Å.; Gíslason, S.; Løkke, S. Guidelines to Increased Collection of Plastic Packaging Waste from Households THE NORDIC REGION-Leading in Green Growth; Nordisk Ministerråd: Copenhagen, Denmark, 2015. [CrossRef]

88. FSC. FSC Certification. Available online: https://us.fsc.org/en-us/certification (accessed on 14 January 2020).

89. Arla. Arla Highlights New Farmers' Farmers with New Marking|Arla. Available online: https://www.arla.se/om-arla/nyheter-press/2015/pressrelease/arla-lyfter-fram-aegarboenderna-medny-maerkning-1202663/ (accessed on 14 January 2020).

90. The Krav Association. The Krav Association Packaging Guide; Krav Organization: Uppsala, Sweden, 2017; Version 2. Available online: https://www.Krav.se (accessed on 9 March 2020).

91. Carrillo, E.; Fiszman, S.; Lähteenmäki, L.; Varela, P. Consumers' Perception of Symbols and Health Claims as Health-Related Label Messages. A Cross-Cultural Study. Food Res. Int. 2014, 62, 653-661. [CrossRef]

92. Tetrapak. Caps from Sugar Cane-Tetra Pak-Innovation Creates Value. Available online: https:// innovationcreatesvalue.tetrapak.com/story/a-sweet-deal-on-caps/ (accessed on 30 August 2019).

93. BullDog. Weird Questions We Get Asked about Sugar Cane|Bulldog Skincare. Available online: https://www. bulldogskincare.com/blog/weird-questions-we-get-asked-about-sugar-cane/ (accessed on 23 November 2019). 
94. Winterich, K.P.; Nenkov, G.Y.; Gonzales, G.E. Knowing What It Makes: How Product Transformation Salience Increases Recycling. J. Mark. 2019, 83, 21-37. [CrossRef]

95. Kurz, T.; Gardner, B.; Verplanken, B.; Abraham, C. Habitual Behaviors or Patterns of Practice? Explaining and Changing Repetitive Climate-Relevant Actions. Wiley Interdiscip. Rev. Clim. Chang. 2015, 6, 113-128. [CrossRef]

96. Becker, L.; van Rompay, T.J.L.; Schifferstein, H.N.J.; Galetzka, M. Tough Package, Strong Taste: The Influence of Packaging Design on Taste Impressions and Product Evaluations. Food Qual. Prefer. 2011, 22, 17-23. [CrossRef]

97. Suleman, A. Science of Typography in Packaging Designs|Think Design. Available online: https://blog. logodesignguru.com/science-of-typography-in-packaging/ (accessed on 22 February 2020).

98. Benoni, H. Top-down Prioritization of Salient Items May Produce the so-Called Stimulus-Driven Capture. Front. Psychol. 2018, 9. [CrossRef] [PubMed]

99. Evergreen, S. For the Love of Font Size. Available online: https://stephanieevergreen.com/for-the-love-offont-size/ (accessed on 26 December 2018).

100. BOXUP Font Basics. Available online: https://www.boxup.com/blog/post/font-basics (accessed on 22 February 2020).

101. Walker, T. The Effect of Typography on User Experience \& Conversions. Available online: https://cxl.com/ blog/the-effects-of-typography-on-user-experience-conversions/ (accessed on 22 February 2020).

102. Montazeri, S.; Gonzalez, R.D.; Yoon, C.; Papalambros, P.Y. Color, Cognition, and Recycling: How The Design of Everyday Objects Prompt Behavior Change. In Proceedings of the International Design Conference-Design 2012, Dubrovnik, Croatia, 21-24 May 2012; pp. 1363-1368. Available online: https://www.designsociety.org/publication/32105/COLOR\%2C+COGNITION\%2C+AND+RECYCLING\% 3A+HOW+THE+DESIGN+OF+EVERYDAY+OBJECTS+PROMPT+BEHAVIOR+CHANGE (accessed on 9 March 2020).

103. Wang, E.S. T The Influence of Visual Packaging Design on Perceived Food Product Quality, Value, and Brand Preference. Int. J. Retail Distrib. Manag. 2013, 41, 805-816. [CrossRef]

104. Chitturi, R.; Carlos Londono, J.; Alberto Amezquita, C. The Influence of Color and Shape of Package Design on Co nsumer Preference: The Case of Orange Juice. Int. J. Innov. Econ. Dev. 2019, 5, 42-56. [CrossRef]

105. Verplanken, B.; Aarts, H. Habit, Attitude, and Planned Behaviour: Is Habit an Empty Construct or an Interesting Case of Goal-Directed Automaticity? Eur. Rev. Soc. Psychol. 1999, 10, 101-134. [CrossRef]

106. Wood, W.; Neal, D.T. A New Look at Habits and the Habit-Goal Interface. Psychol. Rev. 2007, 114, 843-863. [CrossRef]

107. Arla. Sustainable Packaging|Arla. Available online: https://www.arla.com/sustainability/sustainablepackaging/ (accessed on 20 February 2020).

108. European Union. Directive 2008/98/EC on Waste (Waste Framework Directive) European Commission. Available online: https://ec.europa.eu/environment/waste/framework/ (accessed on 16 September 2019).

109. Krav. KRAV|KRAV. Available online: http://www.krav.se/in-english/krav-standards/ (accessed on 20 February 2020).

(C) 2020 by the authors. Licensee MDPI, Basel, Switzerland. This article is an open access article distributed under the terms and conditions of the Creative Commons Attribution (CC BY) license (http://creativecommons.org/licenses/by/4.0/). 